\title{
Article
}

\section{Parametric Analysis of the Edge Capacitance of Uniform Slots and Application to Frequency-Variation Permittivity Sensors}

\author{
Jonathan Muñoz-Enano $^{1, *(\mathbb{D})}$, Jesús Martel ${ }^{2}$, Paris Vélez ${ }^{1} \mathbb{D}$, Francisco Medina $^{2} \mathbb{D}$, Lijuan Su ${ }^{1} \mathbb{D}$ \\ and Ferran Martín ${ }^{1}$ (D) \\ 1 CIMITEC, Departament d'Enginyeria Electrònica, Universitat Autònoma de Barcelona, \\ 08193 Bellaterra, Spain; Paris.Velez@uab.cat (P.V.); Lijuan.Su@uab.cat (L.S.); Ferran.Martin@uab.cat (F.M.) \\ 2 Grupo de Microondas, Universidad de Sevilla, Avenida Reina Mercedes s/n, 41012 Sevilla, Spain; \\ Martel@us.es (J.M.); Medina@us.es (F.M.) \\ * Correspondence: Jonatan.Munoz@uab.cat
}

Citation: Muñoz-Enano, J.; Martel, J.; Vélez, P.; Medina, F.; Su, L.; Martín, F. Parametric Analysis of the Edge Capacitance of Uniform Slots and Application to Frequency-Variation Permittivity Sensors. Appl. Sci. 2021, 11,7000. https://doi.org/10.3390/ app11157000

Academic Editor: Benjamin Potelon

Received: 30 June 2021

Accepted: 26 July 2021

Published: 29 July 2021

Publisher's Note: MDPI stays neutral with regard to jurisdictional claims in published maps and institutional affiliations.

Copyright: (c) 2021 by the authors. Licensee MDPI, Basel, Switzerland. This article is an open access article distributed under the terms and conditions of the Creative Commons Attribution (CC BY) license (https:/ / creativecommons.org/licenses/by/ $4.0 /)$.

\begin{abstract}
This paper presents a parametric analysis relative to the effects of the dielectric constant of the substrate, substrate thickness and slot width on the edge capacitance of a slot-based resonator. The interest is to find the conditions (ranges of the previously cited parameters) compatible with the presence of a quasi-magnetic wall in the plane of the slot (or plane of the metallization). If such magnetic wall is present (or roughly present), the electric field in the plane of the slot is tangential (or quasi-tangential) to it and the edge capacitance can be considered to be the parallel combination of the capacitances at both sides of the slot. Moreover, variations in one of such capacitances, e.g., caused by a change in the material on top of the slot, or by a modification of the dielectric constant of the substrate do not affect the opposite capacitance. Under the magnetic wall approximation, the capacitance of certain electrically small slot-based resonators can be easily linked to the dielectric constant of the material present on top of it. The consequence is that such resonators can be used as sensing elements in a permittivity sensor and the dielectric constant of the so-called material under test (MUT) can be determined from the measured resonance frequency and a simple analytical expression. In this paper, the results of this parametric analysis are validated by considering several sensing structures based on dumbbell defect ground structure (DB-DGS) resonators of different dimensions.
\end{abstract}

Keywords: microwave sensor; permittivity sensor; dielectric constant; slot resonator; magnetic wall

\section{Introduction}

The measurement of the dielectric properties and composition of materials, including solids and liquids, by means of planar microwave resonant-based sensors has been a subject of growing interest in recent years (see [1] and references therein). As compared to bulk sensors (e.g., waveguide or cavity sensors [2,3]), planar sensing devices exhibit low cost and profile and can be implemented in flexible substrates (including plastics, paper, etc.), thereby opening the option to implement conformal sensors [4], wearable sensors [5], submersible sensors [6], etc. Moreover, planar sensors may integrate the necessary electronics for signal generation and post-processing (and eventually for communication purposes) in the same substrate where the sensing element is implemented and such sensors are compatible with other technologies, such as microfluidics [7-10], micromachining, lab-on-a-chip [11], etc. In addition to the advantages of planar technology, sensors operating at microwave frequencies are especially suited for the measurement of the dielectric properties of samples, as far as microwaves exhibit significant penetration depths in most materials, including solid dielectrics, liquids and biomaterials. Thus, noninvasive measurements using microwave signals are possible. Finally, the main relevant characteristics of planar resonant elements, i.e., the resonance frequency, phase and quality factor, are highly sensitive to the dielectric properties (complex permittivity) of the surrounding medium 
and, consequently, resonant methods are good candidates for the implementation of highly sensitive permittivity sensors.

There are several strategies or working principles for the implementation of permittivity sensors based on planar resonators, including frequency variation [12-27], frequency splitting [28-36], phase variation [37-50], coupling modulation [51-61] and differentialmode sensors [62-72] (Nevertheless, some differential sensors are based also on some of the previous working principles, e.g., phase variation [37-41]). Frequency-splitting, coupling-modulation and differential-mode sensors exploit electromagnetic symmetry properties $[73,74]$ and exhibit high robustness against cross-sensitivities related to changes in environmental factors, such as temperature or humidity (Nevertheless, most couplingmodulation sensors are devoted to the measurement of spatial variables, rather than material properties). Frequency-variation and phase-variation sensors, by contrast, are less tolerant to the effects of ambient factors, unless these sensors are implemented differentially. However, the design of these sensors is, in general, very simple. Typically, frequencyvariation and phase-variation sensors are implemented by means of a transmission line and a loading or coupled planar resonant element and examples of transmission-mode (e.g., [16,21,47]) and reflective-mode (e.g., [45,48]) devices have been reported. Recently, phase-variation sensors with unprecedented sensitivity have been presented [45]. In such sensors, a harmonic interrogation signal suffices for sensing. However, phase measurements, especially in reflective-mode structures, i.e., those exhibiting the highest reported sensitivities [45], are not so simple in a real scenario. Frequency-variation sensors measure the variation in the notch or peak resonance frequency and eventually the magnitude (or quality factor) of a transmission line loaded with a sensing resonator that is caused by the variation in the permittivity of the so-called material under test (MUT). For sensing in an operational environment, wideband voltage controlled oscillators (VCOs) that are able to cover the entire output frequency dynamic range are needed (thereby increasing the cost). This is the main drawback of these sensors than compared to single-frequency sensors such as phase-variation, coupling modulation or some differential-mode sensors. However, frequency-variation permittivity sensors have been widely investigated with many papers devoted to sensitivity enhancement and they are still the subject of intensive research because the combinations of design simplicity, achievable sensitivity, robustness and required associated electronics in such sensors are good.

There are many planar resonators useful for sensing by exploiting frequency variation. Of particular interest are those resonators exhibiting a small electrical size [74-76], including metallic and slot-based resonators, since the overall size of the sensing region can be minimized by considering such small-sized sensing elements. The examples of electrically small metallic resonators are the step impedance resonator (SIR) [77], the step impedance shunt stub (SISS) [78], the folded SIR [79], the split ring resonator (SRR) [80], the open split ring resonator (OSRR) [81], the spiral resonator (SR) [82] and the electric LC (ELC) resonator [83], among others. The slot (or complementary) counterparts of the previous resonators, i.e., the dumbbell defect ground structure resonator (DB-DGS) [84], the slotted shunt stub [85], the folded DB-DGS [73], the complementary split ring resonator (CSRR) [86], the open complementary split ring resonator (OCSRR) [87] and the magnetic LC (MLC) resonator [88], are also of interest for sensing. Indeed, slotted resonators etched, e.g., in the ground plane of a microstrip line, may represent a better alternative to their metallic counterparts. The reason is that since the MUT should be in contact or in close proximity to the resonant element, such MUT is necessarily located in the backside part of the substrate. By this means, any potential interference of the MUT (including the microfluidic channel and mechanical accessories in sensors devoted to the measurement of liquid properties) with the line and associated electronics can be circumvented.

In slotted resonators, the change in the resonance frequency is caused by the variation of the capacitance, in turn produced by the effects of the MUT. It is possible to analytically obtain the expression providing the sensitivity as a function of the dielectric constant of the MUT under some reasonable hypothesis and approximations. Specifically, for that purpose, 
it is necessary to express the dependence of the resonator's capacitance on the dielectric constant of the MUT and this can be easily achieved if the capacitance of the resonator can be expressed as the parallel combination of the capacitances of the two halves (above and below) of the resonator plane. Such parallel association of capacitances is valid as far as the electric field in the slot region (in the plane of the slot) is tangential or quasi-tangential to it, i.e., if there is a magnetic or quasi-magnetic wall in the slot (or resonator) plane. In this paper, a parametric analysis to infer the validity of this quasi-magnetic wall approximation is carried out and then the results of the analysis are validated by means of electromagnetic simulations in sensing structures consisting in a microstrip line loaded with a DB-DGS resonator. Nevertheless, the sensitivity analysis, which is focused on obtaining the specific expression providing the sensitivity as a function of the dielectric constant of the MUT, is first developed.

\section{DB-DGS Microstrip Sensor and Sensitivity Analysis}

The typical topology of the DB-DGS based microstrip permittivity sensor is depicted in Figure 1, where the circuit model is included. Such model was validated in previous papers $[65,89]$ by comparing the circuit response given by the extracted parameters with the electromagnetic simulation, where it was concluded that the agreement is very good. The sensitivity of any sensor is defined as the derivative of the output variable with respect to the input variable. In frequency-variation permittivity sensors, there are typically two input variables or measurands, which are the dielectric constant of the MUT, $\varepsilon_{M U T}$, and the loss tangent $\tan \delta_{M U T}$. The pair of measurands may also be the real and the imaginary parts of the relative complex permittivity (the real part is actually the dielectric constant). Nevertheless, the relevant sensitivity, which is the one used for comparison purposes, is the one providing the variation of the resonance frequency of the sensing element, $f_{0}$, with $\varepsilon_{M U T}$. It is obvious that the effects of $\varepsilon_{M U T}$ on the resonance frequency are stronger in high-frequency sensors. Therefore, for the sake of comparison, the relative sensitivity is defined as follows:

$$
S=\frac{1}{f_{0}} \frac{d f_{0}}{d \varepsilon_{M U T}}=\frac{1}{f_{0}} \frac{d f_{0}}{d C^{\prime}{ }_{M U T}} \frac{d C^{\prime}{ }_{M U T}}{d \varepsilon_{M U T}}
$$

and is considered to be the more realistic and significant performance parameter [89]. The resonance frequency is given by the following:

$$
f_{0}=\frac{1}{2 \pi \sqrt{L C^{\prime} M U T}},
$$

where $L$ and $C^{\prime}{ }_{M U T}$ are the inductance and capacitance, respectively, of the DB-DGS resonator loaded with the MUT (Actually, the MUT modifies the capacitance and leaves the inductance unaltered). In order to obtain the last derivative of the right-hand side member in (1), which is $d C^{\prime}{ }_{M U T} / d \varepsilon_{M U T}$, let us assume that the capacitance of the DB-DGS resonator can be expressed as the parallel combination of the capacitances present at both halves of the resonant element, i.e., the upper half, $C_{U, M U T}$, and lower half $C_{L}$. We have the following.

$$
C^{\prime}{ }_{M U T}=C_{U, M U T}+C_{L}
$$

The validity of (3) is subjected to the fact that there is a magnetic or quasi-magnetic wall in the plane of the resonator. Indeed, if both the MUT and the substrate are considered to be semi-infinite in the vertical direction, then the electric field lines in the MUT and substrate are mirror images and there is a perfect magnetic wall in that plane (it is assumed that the thickness of the metallization is negligible). The semi-infinite approximation requires that the MUT and substrate are thick enough so that the electric field intensity in the MUT/air and substrate/air interfaces can be neglected. In principle, the MUT can be chosen in order to satisfy such requirement (for instance, if the MUT is a liquid sample, a container or a fluidic channel with sufficient height can be designed). However, the thickness of the substrate might be dictated by other requirements and cannot always be considered to be 
semi-infinite. Thus, if the substrate has a finite thickness and the electric field intensity in the substrate/air interface is not negligible, it is apparent that the electric field lines will be refracted in that interface due to the discontinuity of the dielectric constant. Consequently and rigorously speaking, the magnetic wall in the resonator plane will no longer exist. However, it is reasonable to assume that if the ratio between the capacitive slot width, $S$, and the substrate thickness, $h$, is significantly smaller than one, which is a situation found in most cases, the electric field lines in the slot region are roughly tangential. Thus, a quasi-magnetic wall in that plane is expected in that case and, consequently, Equation (3) can be considered valid. Nevertheless, the limits of validity of the quasi-magnetic wall approximation will be discussed in the next section.

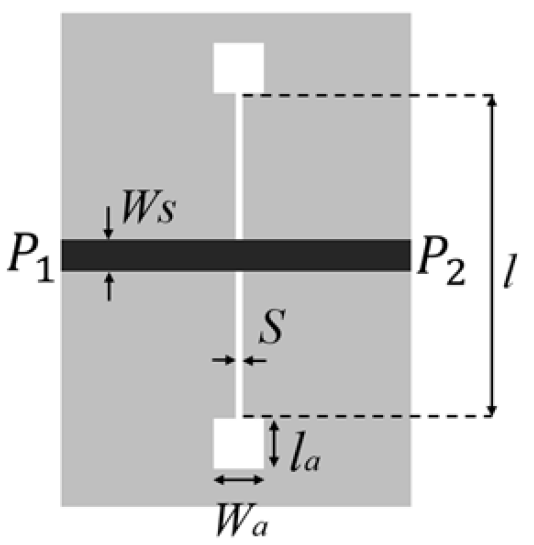

(a)

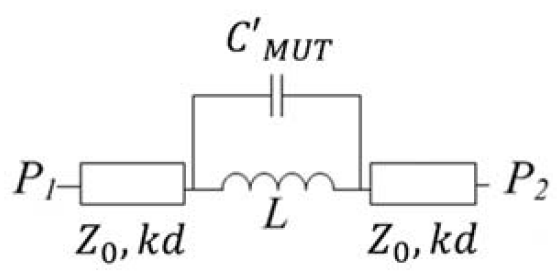

(b)

Figure 1. Typical topology (a) and equivalent circuit model (b) of a DB-DGS-loaded microstrip line. Relevant dimensions are indicated. The strip of the line is indicated in black color, whereas the ground plane where the DB-DGS resonator is etched, is depicted in grey color. In (b), the resonant tank accounts for the DB-DGS resonator, whereas the line sections of characteristic impedance $Z_{0}$ and electrical length $k d$, describe the pair of lines between the ports (P1 and P2) and the position where the resonator is etched ( $k$ is the phase constant and $d$ is the length of these line sections).

Assuming that the capacitance of the slot is separable in two parts, as given by (3), let us next calculate the relative sensitivity (1). For that purpose, it is necessary to express $C^{\prime}{ }_{M U T}$ as a function of $\varepsilon_{M U T}$. If the MUT and the substrate are both semi-infinite, the following result is obtained [21,48]:

$$
C^{\prime}{ }_{M U T}=C^{\prime}{ }_{\text {air }} \frac{\varepsilon_{r}+\varepsilon_{M U T}}{\varepsilon_{r}+1}
$$

where $C^{\prime}{ }_{\text {air }}$ is the capacitance of the bare resonator, i.e., surrounded by air. The capacitance is given by the following:

$$
C^{\prime} \text { air }=C_{U, a i r}+C_{L}
$$

where $\varepsilon_{r}$ is the substrate dielectric constant. In (5), $C_{U, \text { air }}$ is the contribution of the upper semi-space (air) to the total capacitance. By comparing (5) and (3), it is clear that the presence of any MUT on top of the resonator does not alter the contribution to the capacitance associated to the substrate, $C_{L}$, which is an assumption valid under the quasi-magnetic wall approximation. However, (4) is not valid if the semi-infinite substrate approximation does not hold. Under these conditions and assuming that the quasi-magnetic wall approximation still holds, it follows that the capacitance of the resonator loaded with the MUT, $C^{\prime}{ }_{M U T}$, is given by an expression formally identical to (4):

$$
C^{\prime}{ }_{M U T}=C^{\prime}{ }_{\text {air }} \frac{\varepsilon_{r, e q}+\varepsilon_{M U T}}{\varepsilon_{r, e q}+1}
$$


where the single change concerns the dielectric constant of the substrate, which is replaced with an equivalent dielectric constant, $\varepsilon_{r, e q}$, defined as the dielectric constant of a semiinfinite substrate providing an identical contribution to the capacitance, namely, $C_{L}$.

The equivalent dielectric constant can be calculated by isolating it from (6) and by considering a MUT with well-known dielectric constant $\varepsilon_{M U T}$. This provides the following:

$$
\varepsilon_{r, e q}=\frac{\frac{C_{M U T}^{\prime}}{C^{\prime}{ }_{\text {air }}}-\varepsilon_{M U T}}{1-\frac{C^{\prime}{ }_{M U T}}{C^{\prime} \text { air }}}=\frac{f_{0, a i r}^{2}-\varepsilon_{M U T} f_{0, M U T}^{2}}{f_{0, M U T}^{2}-f_{0, a i r}^{2}}
$$

where $f_{0, a i r}$ and $f_{0, M U T}$ are the resonance frequencies of the bare resonator and resonator loaded with the MUT, respectively, i.e., the easily measurable quantities. Once the equivalent dielectric constant is found, the dielectric constant of an unknown MUT is obtained by isolating it from (6). The following is provided.

$$
\varepsilon_{M U T}=\left(\varepsilon_{r, e q}+1\right) \frac{f_{0, a i r}^{2}}{f_{0, M U T}^{2}}-\varepsilon_{r, e q}
$$

Using (2) and (6), the relative sensitivity (1) is found to be as follows:

$$
S=-\frac{1}{2} \cdot \frac{1}{\varepsilon_{r, e q}+\varepsilon_{M U T}}
$$

and it depends solely on the dielectric constant of the MUT. Moreover, it increases by decreasing the dielectric constant and thickness of the substrate, since this has the effect of reducing the equivalent dielectric constant. Nevertheless, it should be mentioned that if the thickness of the substrate is extremely small, in comparison with the slot width, $S$, the validity of the previous analysis might be questionable as far as the considered quasi-magnetic wall approximation might not be satisfied, which is an aspect to that will be analyzed and discussed in the following section.

\section{Parametric Analysis}

In this section, a parametric analysis devoted to gathering the limits of validity of the quasi-magnetic wall approximation is carried out. However, rather than considering a slot structure over a dielectric substrate (Figure 2a), the structure under study is a coplanar waveguide $(\mathrm{CPW})$ with a central strip width 10 times larger than the width of the slots, i.e., $W=10 S$ (see Figure $2 \mathrm{~b}$ ). The reason is that some authors previously developed a software tool useful to calculate the quasi-static capacitance and the effective dielectric constant of a CPW. With such relation between the slot and strip width and symmetric (even-mode) excitation (the fundamental mode of a CPW), the electric field does not appreciably reach the bisecting symmetry plane (a magnetic wall). Thus, the system can be considered to be composed of two independent halves, where the behavior of each half is identical to the one of the slot structure of Figure 2a (actually, the same conclusion is deduced for odd-mode excitation of the CPW structure). Therefore, carrying out the parametric analysis on the CPW transmission line (with $W=10 S$ ) is fully justified.

The effective dielectric constants of the CPW structures (used to check the validation of the behavior of the slots) have been calculated by means of the highly efficient seminumerical algorithm reported in [90], which is basically an enhanced version of the wellknown method of moments (MoM) in the spectral domain. In order to obtain the per-unitlength capacitance $(C)$ and inductance $(L)$ matrices of a general multi-conductor $C P W$, an integral equation is posed for the tangential electrical field in the slots. The kernel of such integral equation in the spectral domain can be analytically determined for a very general class of multilayered substrates. In addition, the use of appropriate basis functions with edge singularities and analytical techniques to speed up the calculation of the entries of the 
MoM matrix results in a very fast and extremely accurate computer code, which has been the considered one (see [90] for further details, which are out of the scope of this paper).

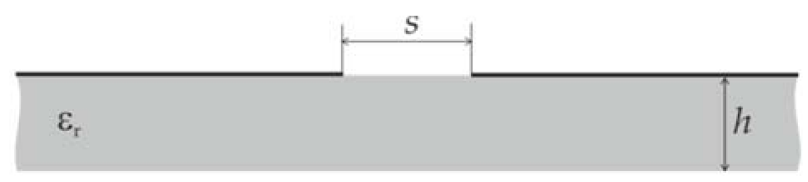

(a)

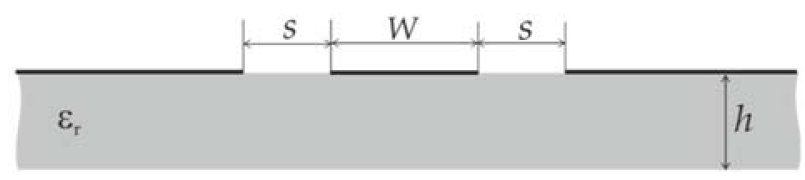

(b)

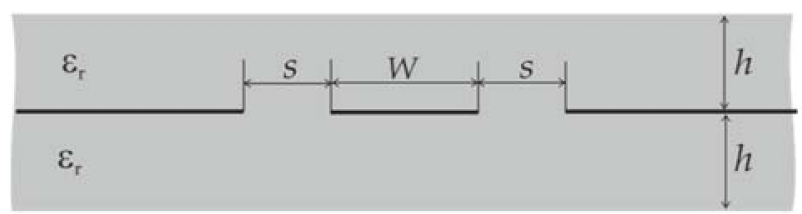

(c)

Figure 2. Cross sectional view of the slot structure (a), equivalent coplanar waveguide (CPW) structure (b) and symmetric CPW structure, with the metal layer equally covered at both sides (c). The vertical symmetry planes in the CPWs of $(\mathbf{b}, \mathbf{c})$ are perfect magnetic walls for the fundamental (even) CPW mode. The horizontal symmetry plane in (c) is a perfect magnetic wall, whereas the horizontal plane in $(\mathbf{a}, \mathbf{b})$ are quasi-magnetic walls, provided $E_{r e l}$ is small.

The parameters under consideration are the slot width $S$, the substrate thickness $h$ and the dielectric constant of the substrate $\varepsilon_{r}$ (as mentioned $W=10 S$ ). It is assumed that the conductivity of the metal layer is infinite and its thickness is null (perfect conductor approximation). Due to the scalability of the Maxwell equations, it follows that the relevant geometry parameter is the ratio between the slot width and substrate height, $r=S / h$. Thus, the parametric analysis reduces the study of the effects to only two parameters, $r$ and $\varepsilon_{r}$. For any given combination of $r$ and $\varepsilon_{r}$, the tool provides the effective dielectric constant, $\varepsilon_{\text {eff, }}$ of the actual (CPW) structure (Figure 2b), as well as the effective dielectric constant of a CPW covered with a dielectric material identical to the substrate (i.e., with the same dielectric constant and thickness), see Figure 2c. Such an effective dielectric constant is indeed the equivalent dielectric constant, $\varepsilon_{r, e q}$, as defined in the previous section. If the quasi-magnetic wall approximation assumed in the previous analysis is valid, the effective dielectric constant, $\varepsilon_{\text {eff }}$, should coincide with the effective dielectric constant of the CPW calculated simply as $\left(1+\varepsilon_{r, e q}\right) / 2 \equiv \varepsilon_{a v}$, i.e., the average value of the dielectric constant of air and $\varepsilon_{r, e q}$. Therefore, an indicative parameter of the validity of the quasi-magnetic wall approximation is the relative difference between $\varepsilon_{e f f}$ and $\varepsilon_{a v}$. When expressed in percentage, such a parameter or relative error is simply $E_{r e l}=100 \cdot\left(\varepsilon_{e f f}-\varepsilon_{a v}\right) / \varepsilon_{\text {eff }}$.

Figure 3 depicts $\varepsilon_{e f f}, \varepsilon_{r, e q}$ and $E_{r e l}$ as a function of $r$ by considering the dielectric constant of the substrate, $\varepsilon_{r}$, as the parameter. It can be appreciated that $E_{r e l}$ grows with $r$, which is as expected on account of the increasing magnitude of the electric field in the substrate/air interface as $r$ increases. Moreover, the relative error increases with the dielectric constant of the substrate. That is, a higher dielectric constant contrast generates stronger refraction of the electric field lines in the substrate/air interface, thereby magnifying the asymmetry between the electric field lines at both sides of the metal layer. Note that in the limit when $\varepsilon_{r} \rightarrow 1$, there is perfect symmetry with regard to the metal plane and such plane is a perfect magnetic wall. Nevertheless, according to Figure 3, the relative error in the worst considered case, $r=20$ and $\varepsilon_{r}=10.2$, is as small as $E_{r e l}=0.43 \%$. Moreover, for reasonable 
DB-DGS resonators and substrates, the ratio between the slot width and the substrate height is expected to be smaller than one $(r<1)$, which is a range where the relative error is found to be negligible according to Figure $3 c$. Consequently, it can be concluded that the horizontal plane of the CPW metal can be considered to be a magnetic wall to a very good approximation and this extends to the slot structure of Figure $2 \mathrm{a}$ as far as the behavior of both structures is very similar.

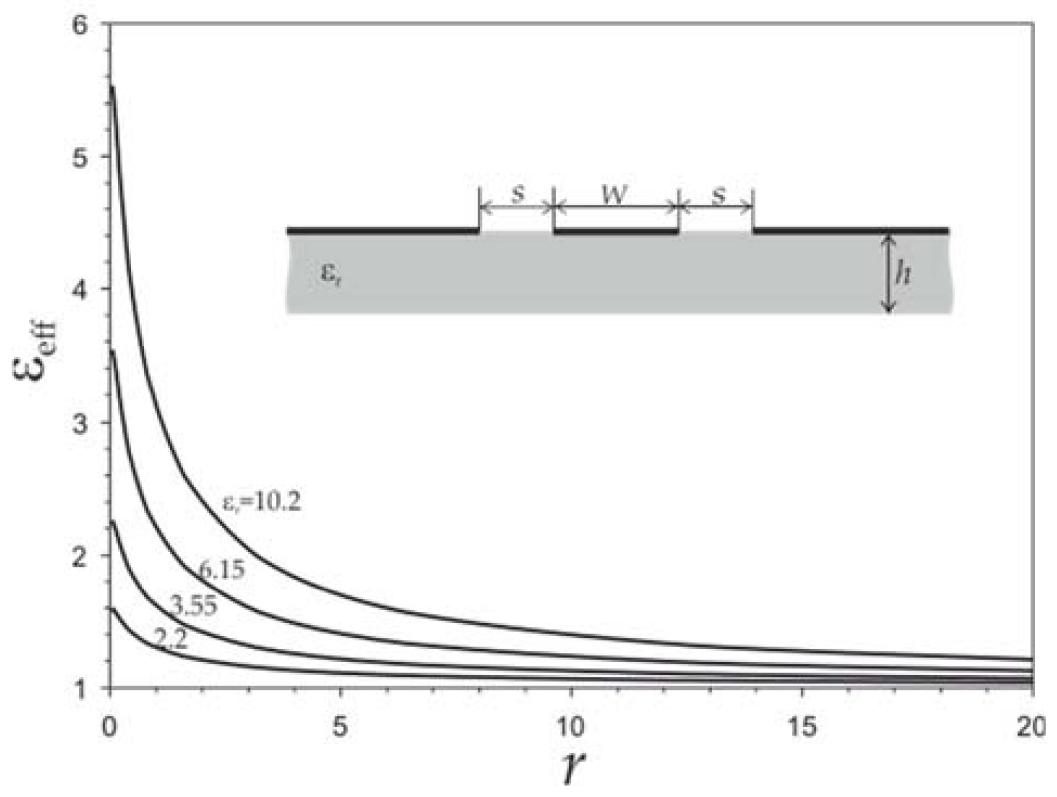

(a)

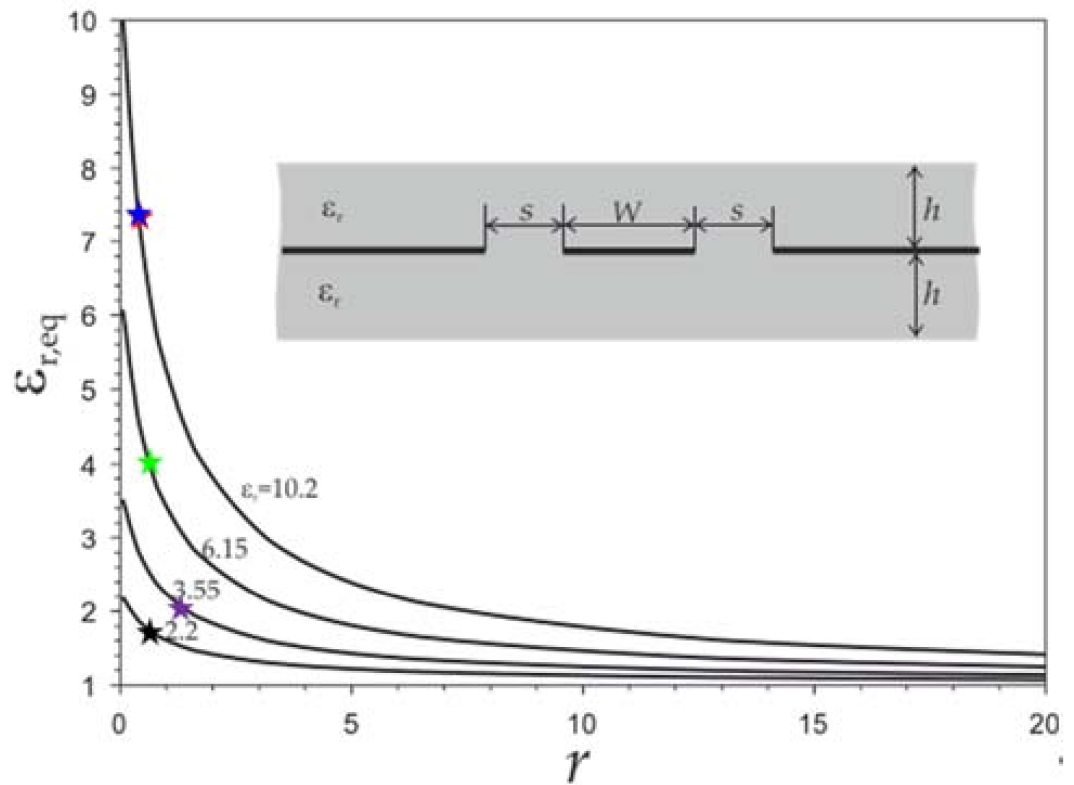

(b)

Figure 3. Cont. 


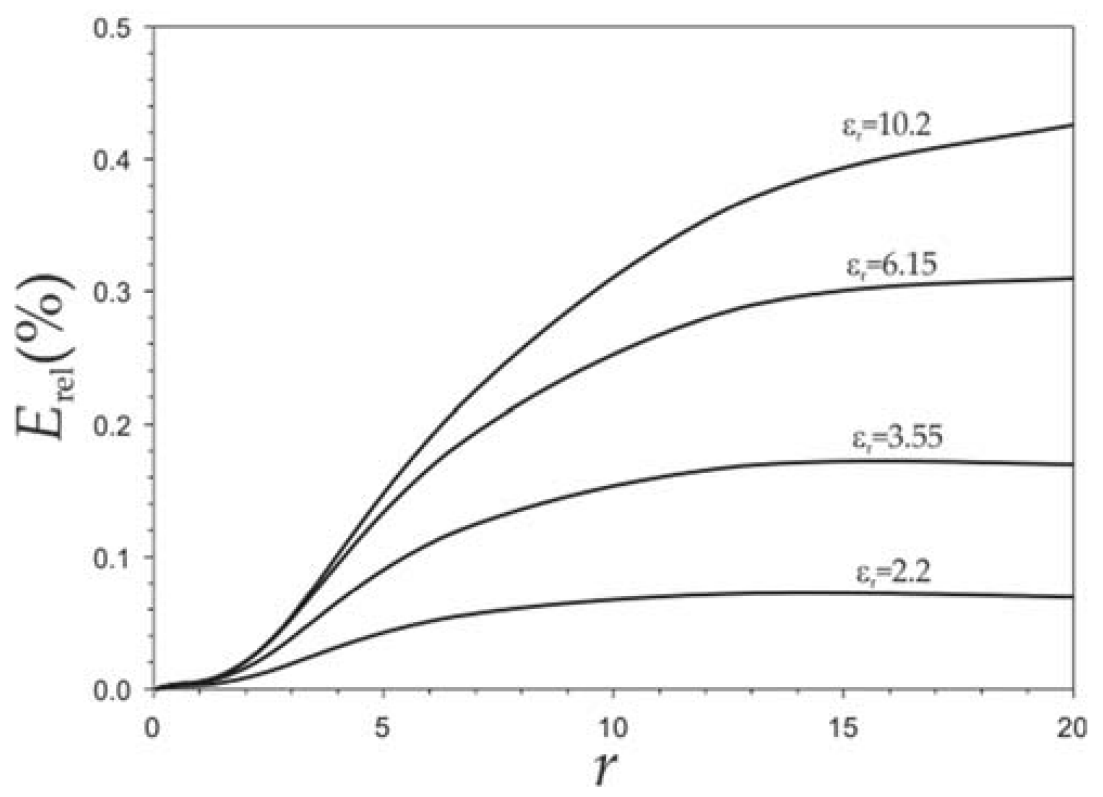

(c)

Figure 3. Dependence of $\varepsilon_{e f f}(\mathbf{a}), \varepsilon_{r, e q}(\mathbf{b})$ and $E_{r e l}(\mathbf{c})$ with $r$, as parametrized by $\varepsilon_{r}$.

It is interesting to mention that, according to Figure $3 b$, as $r$ decreases, the equivalent dielectric constant, $\varepsilon_{r, e q}$, approaches that of the substrate, $\varepsilon_{r}$. The reason is that in the limit when $r \rightarrow 0$, the substrate satisfies the semi-infinite approximation. Moreover, for a given value of $r$, the lower the value of $\varepsilon_{r}$, the closer the value of $\varepsilon_{r, e q}$ to $\varepsilon_{r}$. Note that in the limit when $\varepsilon_{r} \rightarrow 1$ (air), the equivalent dielectric constant must satisfy $\varepsilon_{r, e q} \rightarrow \varepsilon_{r}=1$, regardless of the value of $r$. In the next section, which is devoted to validation by means of electromagnetic simulation of various DB-DGS-loaded microstrip line based sensors and the analysis of the previous section, it will be demonstrated that the agreement between the equivalent dielectric constant of the considered substrates and the results given in Figure $3 b$ is good.

\section{Validation}

The objective of this section is to validate the sensitivity analysis of Section 3, including the procedure to infer the equivalent dielectric constant of the substrate as is detailed in Section 2. For that purpose, several DB-DGS geometries and substrates (with different values of the thickness and dielectric constant) are considered. Table 1 indicates such geometry and substrate parameters for the six considered structures (designated as sensors A, B, C, D, E and F).

Table 1. Geometry and substrate parameters for the considered sensors.

\begin{tabular}{ccccccccc}
\hline Sensor & $\begin{array}{c}f_{\mathbf{0}, \boldsymbol{a i r}} \\
(\mathbf{G H z})\end{array}$ & $\begin{array}{c}\boldsymbol{W}_{\boldsymbol{s}} \\
(\mathbf{m m})\end{array}$ & $\boldsymbol{\varepsilon}_{\boldsymbol{r}}$ & $\boldsymbol{h} \mathbf{( \mathbf { m m } )}$ & $\boldsymbol{S}(\mathbf{m m})$ & $\boldsymbol{l} \mathbf{( \mathbf { m m } )}$ & $\begin{array}{c}\boldsymbol{W}_{\boldsymbol{a}} \\
(\mathbf{m m})\end{array}$ & $\boldsymbol{l}_{\boldsymbol{a}}(\mathbf{m m})$ \\
\hline $\mathrm{A}$ & 3.204 & 3.91 & 2.20 & 1.270 & 0.300 & 21 & 3.7 & 3.7 \\
$\mathrm{~B}$ & 3.226 & 0.562 & 3.55 & 0.254 & 0.300 & 20 & 3.5 & 3.5 \\
$\mathrm{C}$ & 3.22 & 1.13 & 3.55 & 0.508 & 0.600 & 21.6 & 3.5 & 3.5 \\
$\mathrm{D}$ & 3.24 & 0.368 & 6.15 & 0.254 & 0.200 & 20 & 2.3 & 2.3 \\
$\mathrm{E}$ & 3.28 & 1.184 & 10.2 & 1.270 & 0.200 & 13.5 & 1.7 & 1.7 \\
$\mathrm{~F}$ & 3.29 & 1.184 & 10.2 & 1.270 & 0.300 & 15 & 1.6 & 1.6 \\
\hline
\end{tabular}


First, the responses of the bare sensors and the responses of the sensors loaded with different semi-infinite MUTs, which are obtained from full-wave electromagnetic simulation (using Keysight Momentum), are obtained. Since the interest in this paper is to validate the sensitivity analysis based on the concept of the equivalent dielectric constant of the substrate, the simulations have been carried out by considering that the loss tangent of both the substrate and MUTs are identical. The specific considered value is the one of the Rogers RO3010 commercial microwave substrate, i.e., $\tan \delta=0.0035$. The metal layers with a thickness of $35 \mu \mathrm{m}$ and the conductivity of $\mathrm{Cu}$ are the considered parameters. The results of these electromagnetic simulations are depicted in Figure 4.

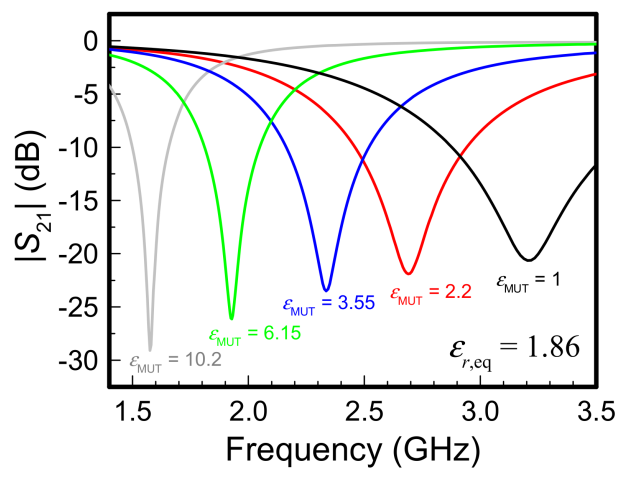

(a)

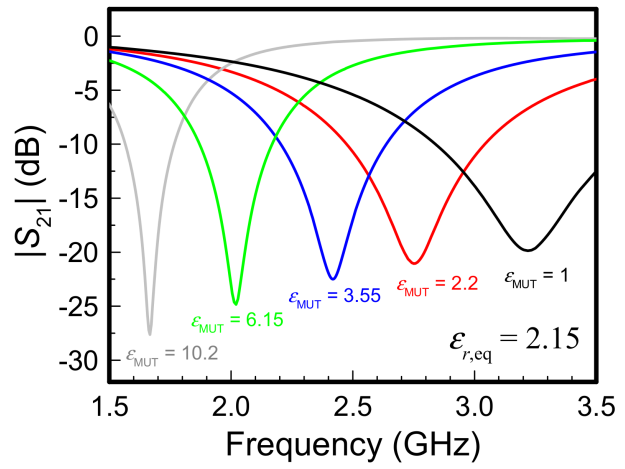

(c)

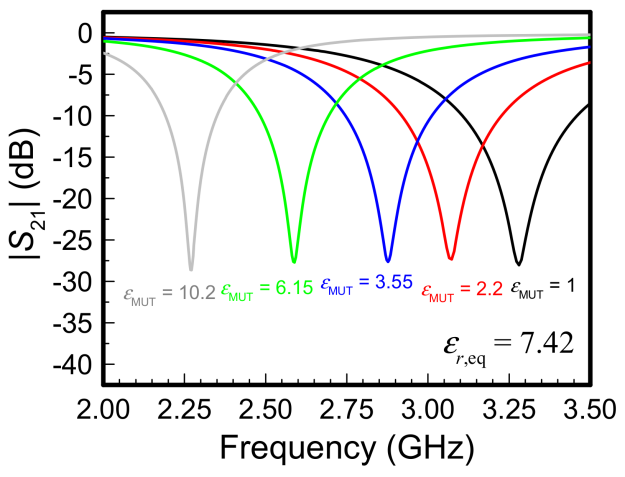

(e)

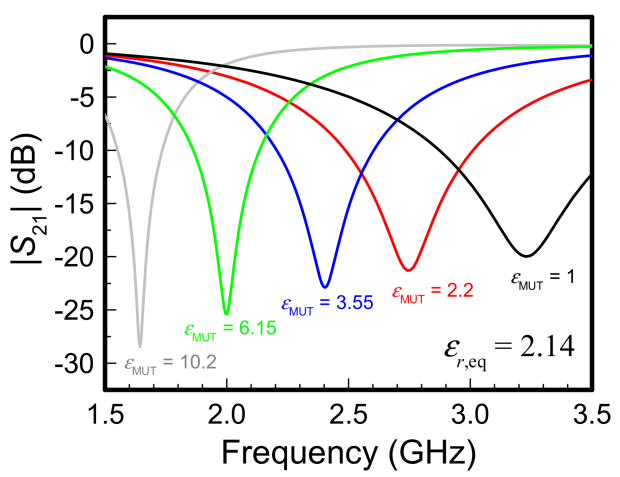

(b)

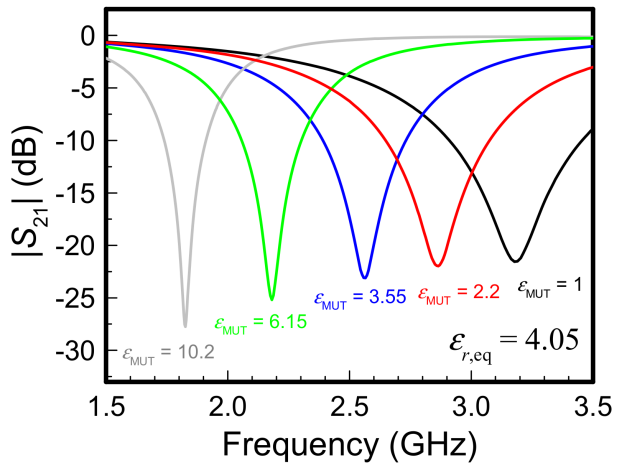

(d)

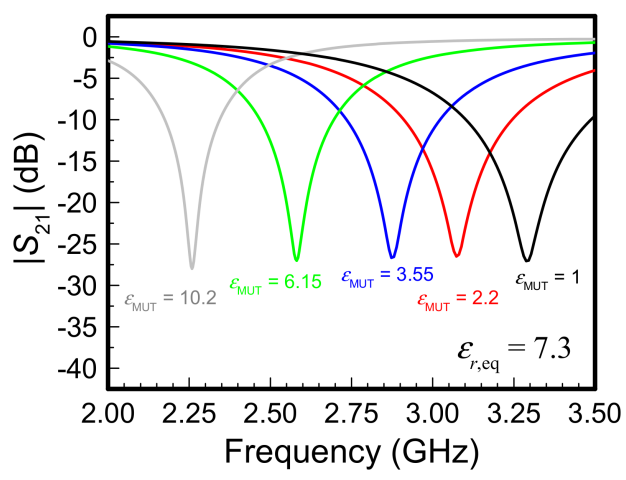

(f)

Figure 4. Responses of the sensors for different dielectric constants of the material under test (MUT) (indicated). (a) Sensor A; (b) sensor B; (c) sensor C; (d) sensor D; (e) sensor E; (f) sensor F.

For the six sensing structures, we have first obtained the equivalent dielectric constant of the substrate (indicated in Figure 4, as insets). For that purpose, we have used Equation (7), where the considered reference MUT is the one with dielectric constant 
$\varepsilon_{M U T}=3.55$ in all cases. Introducing this value in $(7)$ and the resonance frequencies, $f_{0, \text { air }}$ and $f_{0, M U T}$, which are inferred from the simulations, the equivalent dielectric constant of the substrates, $\varepsilon_{r, e q}$, is obtained. The six resulting values (one for each sensing structure) are depicted in Figure $3 b$ for comparison purposes. The excellent agreement with the results calculated from the numerical method (briefly explained before and reported in [90]) validates the approach to deduce the equivalent dielectric constant from the simulated or measured responses. As expected, the equivalent dielectric constants for sensors B and C are identical, since the dielectric constant of the substrate is $\varepsilon_{r}=3.55$ in both cases and the ratio between the slot width and the substrate thickness is also identical (i.e., $S / h=1.181$ ).

Next, we have obtained the shift of the resonance frequency for each sensor as a function of the dielectric constant of the MUT. The results are depicted in Figure 5a. Figure $5 b$ depicts the relative sensitivity derived according to Equation (1), where the derivative $d f_{0} / d \varepsilon_{M U T}$ has been numerically obtained from the data points of Figure 5 a. It follows from Figure $5 \mathrm{~b}$ that the relative sensitivity, $S$, is roughly indistinguishable in those sensors with identical value of the equivalent dielectric constant (sensors B and C). Moreover, $S$ is in very good agreement with the theoretical Equation (9). Such expression, which is a result of the sensitivity analysis, predicts that the sensitivity merely depends on the equivalent dielectric constant of the substrate under the considered approximations and obviously on the dielectric constant of the MUT. If the substrate can be considered to be semi-infinite, i.e., $S / h \rightarrow 0$, once the substrate dielectric constant is set to a certain value, the relative sensitivity does not depend on the geometry of the DB-DGS, since the equivalent dielectric constant roughly coincides with the substrate dielectric constant. In sensors $\mathrm{E}$ and $\mathrm{F}$, the substrate dielectric constant is $\varepsilon_{r}=10.2$ and $S / h$, which although is different, is very small in both cases. For this reason, the equivalent dielectric constant of sensors $\mathrm{E}$ and $\mathrm{F}$ is very similar to the dielectric constant of the substrate and, consequently, the sensitivities are roughly identical despite the different DB-DGS geometries of both sensors.

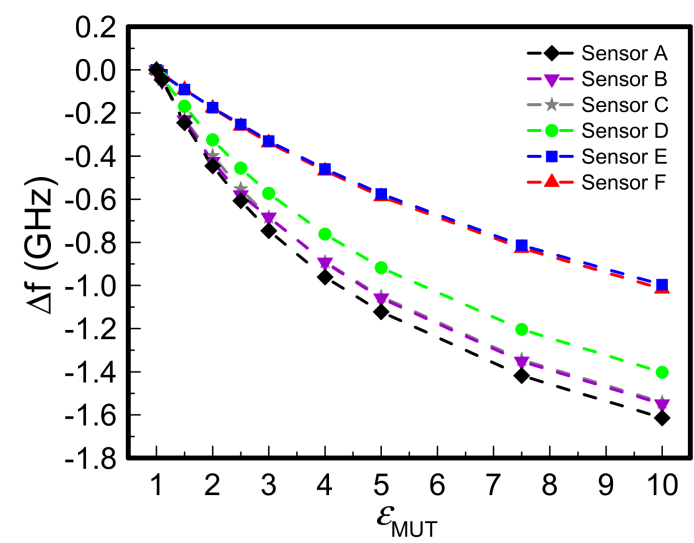

(a)

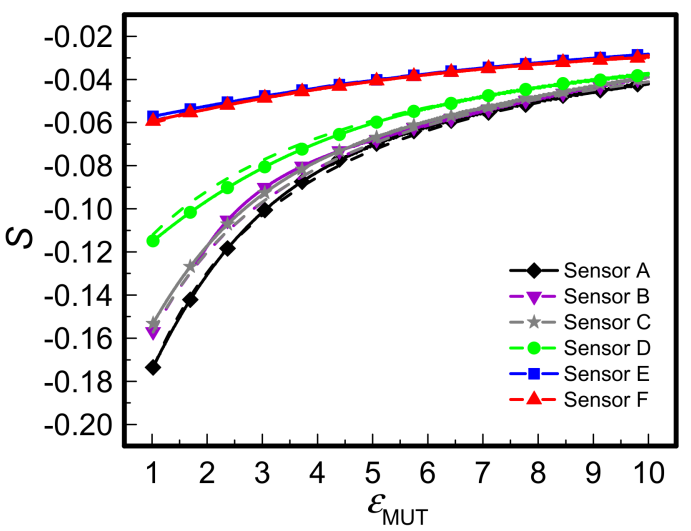

(b)

Figure 5. Variation of the resonance frequency with the dielectric constant of the MUT (a) and relative sensitivity (b) for sensors A, B, C, D, E and F. The theoretical relative sensitivities inferred from Equation (9) are also included in the figure (dashed line).

The results of this section validate the sensitivity analysis and the method for inferring the equivalent dielectric constant of the substrate. The analysis and the method are both based on the hypothesis that the plane of the DB-DGS is a magnetic wall, which is very reasonable by virtue of the parametric analysis of the precedent section. It should be mentioned, however, that in such parametric analysis, the presence of the microstrip line was not taken into account. This line affects the electric field distribution of the slot in the region beneath the line and, consequently, one expects that the influence of the line is limited provided that its width is much smaller than the length of the slots. The fact that the equivalent dielectric constant of the substrate obtained from the simulated responses of the different sensors (loaded with the reference MUT) coincides with the equivalent 
dielectric constant obtained by means of the numerical method (based on the method of moments (MoM) [90]) and further indicates that the effects of the line can be neglected to a good approximation.

\section{Conclusions}

In conclusion, it has been demonstrated in this paper that the plane of a slot capacitance etched on a finite substrate (uncoated on the opposite side of the slot) behaves as a magnetic wall to a very good approximation, at least under reasonable conditions (substrate thickness and dielectric constant, as well as slot width) found in most practical situations. Under the magnetic wall approximation, the slot capacitance can be considered to be composed by the parallel combination of the capacitances at both sides of the slot, while both are independent of one another. By using this parallel association of capacitances as well as the concept of equivalent dielectric constant of the substrate, an analytical expression providing the dependence of the resonance frequency with the dielectric constant of the material under test (MUT) in dumbbell defect-ground-structure (DB-DGS) based microstrip permittivity sensors has been obtained. Such equivalent dielectric constant of the substrate (defined as the necessary dielectric constant of a semi-infinite substrate providing the same contribution to the capacitance of the slot) is a fundamental parameter that, together with the dielectric constant of the MUT, determines the relative sensitivity, which is the key figure of merit of permittivity sensors based on frequency variation. Specifically, a very simple analytical expression of the relative sensitivity that does not explicitly depend on the geometry of the DB-DGS has been inferred. It depends solely on the dielectric constant of the MUT and on the equivalent dielectric constant of the substrate. Therefore, any combination of DB-DGS geometry, substrate thickness and substrate dielectric constant providing the same equivalent dielectric constant of the substrate is expected to provide the same relative sensitivity. It is also concluded that if the substrate can be considered to be semi-infinite in the vertical direction, the equivalent dielectric constant coincides with the dielectric constant of the substrate and the relative sensitivity neither depends on the DB-DGS geometry nor on the substrate thickness.

Author Contributions: Conceptualization and idea J.M.-E. and F.M. (Ferran Martín); theoretical analysis, J.M.-E., P.V. and F.M. (Ferran Martín); parametric analysis J.M. and F.M. (Francisco Medina); validation, J.M.-E. and L.S.; writing-original draft preparation, F.M. (Ferran Martín); writingreview and editing, F.M. (Ferran Martín); supervision, P.V. and F.M. (Ferran Martín). All authors have read and agreed to the published version of the manuscript.

Funding: This work was supported by MICINN-Spain (project PID2019-103904RB-I00), Generalitat de Catalunya (project 2017SGR-1159), ICREA (who awarded Ferran Martín), and by FEDER funds. J. Muñoz-Enano acknowledges the Secreteraria d'Universitats i Recerca (Gen. Cat.) and European Social Fund for the FI grant. L. Su acknowledges the Juan de la Cierva Program for supporting her through Project IJC2019-040786-I.

Institutional Review Board Statement: Not applicable.

Informed Consent Statement: Not applicable.

Data Availability Statement: Not applicable.

Conflicts of Interest: The authors declare no conflict of interest. The funders had no role in the design of the study; in the collection, analyses or interpretation of data; in the writing of the manuscript or in the decision to publish the results.

\section{References}

1. Muñoz-Enano, J.; Velez, P.; Gil, M.; Martin, F. Planar Microwave Resonant Sensors: A Review and Recent Developments. Appl. Sci. 2020, 10, 30. [CrossRef]

2. Gennarelli, G.; Romeo, S.; Scarfi, M.R.; Soldovieri, F. A Microwave Resonant Sensor for Concentration Measurements of Liquid Solutions. IEEE Sens. J. 2013, 13, 1857-1864. [CrossRef]

3. Jha, A.K.; Akhtar, M.J. A Generalized Rectangular Cavity Approach for Determination of Complex Permittivity of Materials. IEEE Trans. Instrum. Meas. 2014, 63, 2632-2641. [CrossRef] 
4. Wei, P.H.; Morey, B.; Dyson, T.; McMahon, N.; Hsu, Y.Y.; Gazman, S.; Klinker, L.; Ives, B.; Dowling, K.; Rafferty, C. A Conformal Sensor for Wireless Sweat Level Monitoring. In Proceedings of the 2013 IEEE Sensors (SENSORS2013), Baltimore, MD, USA, 3-6 November 2013; pp. 991-994.

5. Rodgers, M.M.; Pai, V.M.; Conroy, R.S. Recent Advances in Wearable Sensors for Health Monitoring. IEEE Sens. J. 2015, 15, 3119-3126. [CrossRef]

6. Galindo-Romera, G.; Herraiz-Martinez, F.J.; Gil, M.; Martinez-Martinez, J.J.; Segovia-Vargas, D. Submersible Printed Split-Ring Resonator-Based Sensor for Thin-Film Detection and Permittivity Characterization. IEEE Sens. J. 2016, 16, 3587-3596. [CrossRef]

7. Grenier, K.; Dubuc, D.; Poleni, P.E.; Kumemura, M.; Toshiyoshi, H.; Fujii, T.; Fujita, H. Integrated Broadband Microwave and Microfluidic Sensor Dedicated to Bioengineering. IEEE Trans. Microw. Theory 2009, 57, 3246-3253. [CrossRef]

8. Chretiennot, T.; Dubuc, D.; Grenier, K. A Microwave and Microfluidic Planar Resonator for Efficient and Accurate Complex Permittivity Characterization of Aqueous Solutions. IEEE Trans. Microw. Theory 2013, 61, 972-978. [CrossRef]

9. Salim, A.; Kim, S.H.; Park, J.Y.; Lim, S. Microfluidic Biosensor Based on Microwave Substrate-Integrated Waveguide Cavity Resonator. J. Sens. 2018, 2018. [CrossRef]

10. Zarifi, M.H.; Sadabadi, H.; Hejazi, S.H.; Daneshmand, M.; Sanati-Nezhad, A. Noncontact and Nonintrusive MicrowaveMicrofluidic Flow Sensor for Energy and Biomedical Engineering. Sci. Rep. 2018, 8. [CrossRef]

11. Castillo-León, J.; Svendsen, W.E. Lab-on-a-Chip Devices and Micro-Total Analysis Systems; Springer International Publishing: Cham, Switzerland, 2015.

12. Mandel, C.; Kubina, B.; Schussler, M.; Jakoby, R. Passive Chipless Wireless Sensor for Two-Dimensional Displacement Measurement. In Proceedings of the 41st European Microwave Conference (EuMC 2011), Manchester, UK, 10-13 October 2011; pp. 79-82.

13. Vargas, M.P. Planar Metamaterial Based Microwave Sensor Arrays for Biomedical Analysis and Treatment; Springer: Berlin/Heidelberg, Germany, 2016.

14. Ebrahimi, A.; Withayachumnankul, W.; Al-Sarawi, S.; Abbott, D. High-Sensitivity Metamaterial-Inspired Sensor for Microfluidic Dielectric Characterization. IEEE Sens. J. 2014, 14, 1345-1351. [CrossRef]

15. Schussler, M.; Mandel, C.; Puentes, M.; Jakoby, R. Metamaterial Inspired Microwave Sensors. IEEE Microw. Mag. 2012, 13, 57-68. [CrossRef]

16. Boybay, M.S.; Ramahi, O.M. Material Characterization Using Complementary Split-Ring Resonators. IEEE Trans. Instrum. Meas. 2012, 61, 3039-3046. [CrossRef]

17. Lee, C.S.; Yang, C.L. Complementary Split-Ring Resonators for Measuring Dielectric Constants and Loss Tangents. IEEE Microwave Wirel. Components Lett. 2014, 24, 563-565. [CrossRef]

18. Yang, C.L.; Lee, C.S.; Chen, K.W.; Chen, K.Z. Noncontact Measurement of Complex Permittivity and Thickness by Using Planar Resonators. IEEE Trans. Microw. Theory 2016, 64, 247-257. [CrossRef]

19. Withayachumnankul, W.; Jaruwongrungsee, K.; Tuantranont, A.; Fumeaux, C.; Abbott, D. Metamaterial-based microfluidic sensor for dielectric characterization. Sens. Actuators A Phys. 2013, 189, 233-237. [CrossRef]

20. Salim, A.; Lim, S. Complementary Split-Ring Resonator-Loaded Microfluidic Ethanol Chemical Sensor. Sensors 2016, 16, 1802. [CrossRef]

21. Su, L.J.; Mata-Contreras, J.; Velez, P.; Fernandez-Prieto, A.; Martin, F. Analytical Method to Estimate the Complex Permittivity of Oil Samples. Sensors 2018, 18, 984. [CrossRef]

22. Abdolrazzaghi, M.; Zarifi, M.H.; Daneshmand, M. Sensitivity Enhancement of Split Ring Resonator based Liquid Sensors. In Proceedings of the 2016 IEEE Sensors, Orlando (SENSORS2016), Orlando, FL, USA, 10-13 October 2016.

23. Abdolrazzaghi, M.; Zarifi, M.H.; Pedrycz, W.; Daneshmand, M. Robust Ultra-High Resolution Microwave Planar Sensor Using Fuzzy Neural Network Approach. IEEE Sens. J. 2017, 17, 323-332. [CrossRef]

24. Zarifi, M.H.; Daneshmand, M. Monitoring Solid Particle Deposition in Lossy Medium Using Planar Resonator Sensor. IEEE Sens. J. 2017, 17, 7981-7989. [CrossRef]

25. Zarifi, M.H.; Deif, S.; Abdolrazzaghi, M.; Chen, B.; Ramsawak, D.; Amyotte, M.; Vahabisani, N.; Hashisho, Z.; Chen, W.X.; Daneshmand, M. A Microwave Ring Resonator Sensor for Early Detection of Breaches in Pipeline Coatings. IEEE Trans. Ind. Electron. 2018, 65, 1626-1635. [CrossRef]

26. Abdolrazzaghi, M.; Daneshmand, M.; Iyer, A.K. Strongly Enhanced Sensitivity in Planar Microwave Sensors Based on Metamaterial Coupling. IEEE Trans. Microw. Theory 2018, 66, 1843-1855. [CrossRef]

27. Ebrahimi, A.; Scott, J.; Ghorbani, K. Ultrahigh-Sensitivity Microwave Sensor for Microfluidic Complex Permittivity Measurement. IEEE Trans. Microw. Theory 2019, 67, 4269-4277. [CrossRef]

28. Horestani, A.K.; Naqui, J.; Shaterian, Z.; Abbott, D.; Fumeaux, C.; Martin, F. Two-dimensional alignment and displacement sensor based on movable broadside-coupled split ring resonators. Sens. Actuators A Phys. 2014, 210, 18-24. [CrossRef]

29. Naqui, J.; Damm, C.; Wiens, A.; Jakoby, R.; Su, L.J.; Martin, F. Transmission Lines Loaded with Pairs of Magnetically Coupled Stepped Impedance Resonators (SIRs): Modeling and Application to Microwave Sensors. In Proceedings of the 2014 IEEE MTT-S International Microwave Symposium (IMS2014), Tampa, FL, USA, 1-6 June 2014.

30. Su, L.J.; Naqui, J.; Mata-Contreras, J.; Martin, F. Modeling and Applications of Metamaterial Transmission Lines Loaded With Pairs of Coupled Complementary Split-Ring Resonators (CSRRs). IEEE Antenn. Wirel. Propag. Lett. 2016, 15, 154-157. [CrossRef] 
31. Su, L.J.; Naqui, J.; Mata, J.; Martin, F. Dual-Band Epsilon-Negative (ENG) Transmission Line Metamaterials based on Microstrip Lines Loaded with Pairs of Coupled Complementary Split Ring Resonators (CSRRs): Modeling, Analysis and Applications. In Proceedings of the 9th International Congress on Advanced Electromagnetic Materials in Microwaves and Optics (Metamaterials 2015), Oxford, UK, 7-12 September 2015; pp. 298-300.

32. Su, L.J.; Naqui, J.; Mata-Contreras, J.; Velez, P.; Martin, F. Transmission line metamaterials based on pairs of coupled split ring resonators (SRRs) and complementary split ring resonators (CSRR): A comparison to the light of the lumped element equivalent circuits. In Proceedings of the International Conference on Electromagnetics in Advanced Applications (ICEAA), Torino, Italy, 7-11 September 2015.

33. Naqui, J.; Damm, C.; Wiens, A.; Jakoby, R.; Su, L.J.; Mata-Contreras, J.; Martin, F. Transmission Lines Loaded With Pairs of Stepped Impedance Resonators: Modeling and Application to Differential Permittivity Measurements. IEEE Trans. Microw. Theory 2016, 64, 3864-3877. [CrossRef]

34. Su, L.J.; Mata-Contreras, J.; Velez, P.; Martin, F. Splitter/Combiner Microstrip Sections Loaded With Pairs of Complementary Split Ring Resonators (CSRRs): Modeling and Optimization for Differential Sensing Applications. IEEE Trans. Microw. Theory 2016, 64, 4362-4370. [CrossRef]

35. Velez, P.; Su, L.J.; Grenier, K.; Mata-Contreras, J.; Dubuc, D.; Martin, F. Microwave Microfluidic Sensor Based on a Microstrip Splitter/Combiner Configuration and Split Ring Resonators (SRRs) for Dielectric Characterization of Liquids. IEEE Sens. J. 2017, 17, 6589-6598. [CrossRef]

36. Ebrahimi, A.; Scott, J.; Ghorbani, K. Differential Sensors Using Microstrip Lines Loaded With Two Split-Ring Resonators. IEEE Sens. J. 2018, 18, 5786-5793. [CrossRef]

37. Damm, C.; Schussler, M.; Puentes, M.; Maune, H.; Maasch, M.; Jakoby, R. Artificial Transmission Lines for High Sensitive Microwave Sensors. In Proceedings of the 2009 IEEE Sensors (SENSORS2009), Christchurch, New Zealand, 25-28 October 2009; pp. 755-758.

38. Ferrandez-Pastor, F.J.; Garcia-Chamizo, J.M.; Nieto-Hidalgo, M. Electromagnetic Differential Measuring Method: Application in Microstrip Sensors Developing. Sensors 2017, 17, 1650. [CrossRef]

39. Muñoz-Enano, J.; Velez, P.; Barba, M.G.; Martin, F. An Analytical Method to Implement High-Sensitivity Transmission Line Differential Sensors for Dielectric Constant Measurements. IEEE Sens. J. 2020, 20, 178-184. [CrossRef]

40. Gil, M.; Velez, P.; Aznar-Ballesta, F.; Muñoz-Enano, J.; Martin, F. Differential Sensor Based on Electroinductive Wave Transmission Lines for Dielectric Constant Measurements and Defect Detection. IEEE Trans. Antenn. Propag. 2020, 68, 1876-1886. [CrossRef]

41. Muñoz-Enano, J.; Velez, P.; Barba, M.G.; Mata-Contreras, J.; Martin, F. Differential-Mode to Common-Mode Conversion Detector Based on Rat-Race Hybrid Couplers: Analysis and Application to Differential Sensors and Comparators. IEEE Trans. Microw. Theory 2020, 68, 1312-1325. [CrossRef]

42. Muñoz-Enano, J.; Velez, P.; Su, L.J.; Gil-Barba, M.; Martin, F. A Reflective-Mode Phase-Variation Displacement Sensor. IEEE Access 2020, 8, 189565-189575. [CrossRef]

43. Casacuberta, P.; Muñoz-Enano, J.; Velez, P.; Su, L.J.; Gil, M.; Martin, F. Highly Sensitive Reflective-Mode Defect Detectors and Dielectric Constant Sensors Based on Open-Ended Stepped-Impedance Transmission Lines. Sensors 2020, $20,6236$. [CrossRef] [PubMed]

44. Coromina, J.; Muñoz-Enano, J.; Vélez, P.; Ebrahimi, A.; Scott, J.; Ghorbani, K.; Martín, F. Capacitively-Loaded Slow-Wave Transmission Lines for Sensitivity Improvement in Phase-Variation Permittivity Sensors. In Proceedings of the 202050 th European Microwave Conference (EuMC), Utrecht, The Netherlands, 12-14 January 2021; pp. 491-494.

45. Muñoz-Enano, J.; Vélez, P.; Su, L.; Gil, M.; Casacuberta, P.; Martín, F. On the Sensitivity of Reflective-Mode Phase-Variation Sensors Based on Open-Ended Stepped-Impedance Transmission Lines: Theoretical Analysis and Experimental Validation. IEEE Trans. Microw. Theory Tech. 2021, 69, 308-324. [CrossRef]

46. Su, L.J.; Muñoz-Enano, J.; Velez, P.; Orta, P.C.; Gil, M.; Martin, F. Highly Sensitive Phase Variation Sensors Based on StepImpedance Coplanar Waveguide (CPW) Transmission Lines. IEEE Sens. J. 2021, 21, 2864-2872. [CrossRef]

47. Su, L.J.; Muñoz-Enano, J.; Velez, P.; Casacuberta, P.; Gil, M.; Martin, F. Phase-Variation Microwave Sensor for Permittivity Measurements Based on a High-Impedance Half-Wavelength Transmission Line. IEEE Sens. J. 2021, 21, 10647-10656. [CrossRef]

48. Su, L.J.; Muñoz-Enano, J.; Velez, P.; Gil-Barba, M.; Casacuberta, P.; Martin, F. Highly Sensitive Reflective-Mode Phase-Variation Permittivity Sensor Based on a Coplanar Waveguide Terminated With an Open Complementary Split Ring Resonator (OCSRR). IEEE Access 2021, 9, 27928-27944. [CrossRef]

49. Muñoz-Enano, J.; Coromina, J.; Velez, P.; Su, L.J.; Gil, M.; Casacuberta, P.; Martin, F. Planar Phase-Variation Microwave Sensors for Material Characterization: A Review and Comparison of Various Approaches. Sensors 2021, 21, 1542. [CrossRef]

50. Ebrahimi, A.; Coromina, J.; Muñoz-Enano, J.; Velez, P.; Scott, J.; Ghorbani, K.; Martin, F. Highly Sensitive Phase-Variation Dielectric Constant Sensor Based on a Capacitively-Loaded Slow-Wave Transmission Line. IEEE Trans. Circuits I 2021, 68, 2787-2799. [CrossRef]

51. Naqui, J.; Duran-Sindreu, M.; Martin, F. Novel Sensors Based on the Symmetry Properties of Split Ring Resonators (SRRs). Sensors 2011, 11, 7545-7553. [CrossRef] [PubMed]

52. Naqui, J.; Durán-Sindreu, M.; Martín, F. On the symmetry properties of coplanar waveguides loaded with symmetric resonators: Analysis and potential applications. In Proceedings of the 2012 IEEE/MTT-S International Microwave Symposium Digest (MTT2012), Montreal, QC, Canada, 17-22 June 2012; pp. 1-3. 
53. Naqui, J.; Duran-Sindreu, M.; Martin, F. Alignment and Position Sensors Based on Split Ring Resonators. Sensors 2012, 12, 11790-11797. [CrossRef]

54. Naqui, J.; Martin, F. Transmission Lines Loaded With Bisymmetric Resonators and Their Application to Angular Displacement and Velocity Sensors. IEEE Trans. Microw. Theory 2013, 61, 4700-4713. [CrossRef]

55. Horestani, A.K.; Fumeaux, C.; Al-Sarawi, S.F.; Abbott, D. Displacement Sensor Based on Diamond-Shaped Tapered Split Ring Resonator. IEEE Sens. J. 2013, 13. [CrossRef]

56. Horestani, A.K.; Abbott, D.; Fumeaux, C. Rotation Sensor Based on Horn-Shaped Split Ring Resonator. IEEE Sens. J. 2013, 13, 3014-3015. [CrossRef]

57. Ebrahimi, A.; Withayachumnankul, W.; Al-Sarawi, S.F.; Abbott, D. Metamaterial-Inspired Rotation Sensor with Wide Dynamic Range. IEEE Sens. J. 2014, 14, 2609-2614. [CrossRef]

58. Horestani, A.K.; Naqui, J.; Abbott, D.; Fumeaux, C.; Martin, F. Two-dimensional displacement and alignment sensor based on reflection coefficients of open microstrip lines loaded with split ring resonators. Electron. Lett. 2014, 50, 620-622. [CrossRef]

59. Naqui, J.; Martin, F. Angular Displacement and Velocity Sensors Based on Electric-LC (ELC) Loaded Microstrip Lines. IEEE Sens. J. 2014, 14, 939-940. [CrossRef]

60. Naqui, J.; Coromina, J.; Karami-Horestani, A.; Fumeaux, C.; Martin, F. Angular Displacement and Velocity Sensors Based on Coplanar Waveguides (CPWs) Loaded with S-Shaped Split Ring Resonators (S-SRR). Sensors 2015, 15, 9628-9650. [CrossRef]

61. Velez, P.; Muñoz-Enano, J.; Ebrahimi, A.; Herrojo, C.; Paredes, F.; Scott, J.; Ghorbani, K.; Martin, F. Single-Frequency AmplitudeModulation Sensor for Dielectric Characterization of Solids and Microfluidics. IEEE Sens. J. 2021, 21, 12189-12201. [CrossRef]

62. Shi, D.Y.; Guo, J.H.; Chen, L.; Xia, C.C.; Yu, Z.F.; Ai, Y.; Li, C.M.; Kang, Y.J.; Wang, Z.M. Differential microfluidic sensor on printed circuit board for biological cells analysis. Electrophoresis 2015, 36, 1854-1858. [CrossRef] [PubMed]

63. Velez, P.; Grenier, K.; Mata-Contreras, J.; Dubuc, D.; Martin, F. Highly-Sensitive Microwave Sensors Based on Open Complementary Split Ring Resonators (OCSRRs) for Dielectric Characterization and Solute Concentration Measurement in Liquids. IEEE Access 2018, 6, 48324-48338. [CrossRef]

64. Vélez, P.; Muñoz-Enano, J.; Grenier, K.; Mata-Contreras, J.; Dubuc, D.; Martín, F. Split Ring Resonator-Based Microwave Fluidic Sensors for Electrolyte Concentration Measurements. IEEE Sens. J. 2019, 19, 2562-2569. [CrossRef]

65. Velez, P.; Muñoz-Enano, J.; Gil, M.; Mata-Contreras, J.; Martin, F. Differential Microfluidic Sensors Based on Dumbbell-Shaped Defect Ground Structures in Microstrip Technology: Analysis, Optimization, and Applications. Sensors 2019, 19, 31889. [CrossRef]

66. Muñoz-Enano, J.; Vélez, P.; Gil, M.; Mata-Contreras, J.; Martín, F. Microwave Comparator based on Defect Ground Structures. In Proceedings of the 2019 European Microwave Conference in Central Europe (EuMCE), Prague, Czech Republic, 13-15 May 2019; pp. 244-247.

67. Vélez, P.; Muñoz-Enano, J.; Martín, F. Electrolyte Concentration Measurements in DI Water with 0.125 g/L Resolution by means of CSRR-Based Structures. In Proceedings of the 2019 49th European Microwave Conference (EuMC), Paris, France, 1-3 October 2019; pp. 340-343.

68. Muñoz-Enano, J.; Vélez, P.; Gil, M.; Mata-Contreras, J.; Grenier, K.; Dubuc, D.; Martín, F. Microstrip Lines Loaded with Metamaterial-Inspired Resonators for Microwave Sensors/Comparators with Optimized Sensitivity. In Proceedings of the 2019 49th European Microwave Conference (EuMC), Paris, France, 1-3 October 2019; pp. 754-757.

69. Muñoz-Enano, J.; Velez, P.; Gil, M.; Martin, F. Microfluidic reflective-mode differential sensor based on open split ring resonators (OSRRs). Int. J. Microw. Wirel. Technol. 2020, 12, 588-597. [CrossRef]

70. Ebrahimi, A.; Scott, J.; Ghorbani, K. Transmission Lines Terminated With LC Resonators for Differential Permittivity Sensing. IEEE Microw. Wirel. Compon. Lett. 2018, 28, 1149-1151. [CrossRef]

71. Ebrahimi, A.; Scott, J.; Ghorbani, K. Microwave reflective biosensor for glucose level detection in aqueous solutions. Sens. Actuators A Phys. 2020, 301, 1662. [CrossRef]

72. Velez, P.; Muñoz-Enano, J.; Martin, F. Differential Sensing Based on Quasi-Microstrip Mode to Slot-Mode Conversion. IEEE IEEE Microw. Wirel. Compon. Lett. 2019, 29, 690-692. [CrossRef]

73. Naqui, J. Symmetry Properties in Transmission Lines Loaded with Electrically Small Resonators Circuit Modeling and Applications; Springer International Publishing: Cham, Switzerland, 2016.

74. Martín, F. Artificial Transmission Lines for RF and Microwave Applications; John Wiley: Hoboken, NJ, USA, 2015.

75. Marques, R.; Martin, F.; Sorolla, M. Metamaterials with Negative Parameters: Theory, Design, and Microwave Applications; WileyInterscience: Hoboken, NJ, USA; Lightning Source UK Ltd.: Milton Keynes, UK, 2013.

76. Duran-Sindreu, M.; Naqui, J.; Paredes, F.; Bonache, J.; Martin, F. Electrically Small Resonators for Planar Metamaterial, Microwave Circuit and Antenna Design: A Comparative Analysis. Appl. Sci. 2012, 2, 375-395. [CrossRef]

77. Makimoto, M.; Yamashita, S. Compact bandpass filters using stepped impedance resonators. Proc. IEEE 1979, 67, 16-19. [CrossRef]

78. Naqui, J.; Duran-Sindreu, M.; Bonache, J.; Martin, F. Implementation of shunt-connected series resonators through steppedimpedance shunt stubs: Analysis and limitations. IET Microw. Antennas Propag. 2011, 5, 1336-1342. [CrossRef]

79. Naqui, J.; Martín, F. Mechanically Reconfigurable Microstrip Lines Loaded with Stepped Impedance Resonators and Potential Applications. Int. J. Antennas Propag. 2014, 2014, 1-8. [CrossRef]

80. Pendry, J.B.; Holden, A.J.; Robbins, D.J.; Stewart, W.J. Magnetism from conductors and enhanced nonlinear phenomena. IEEE Trans. Microw. Theory 1999, 47, 2075-2084. [CrossRef] 
81. Martel, J.; Marques, R.; Falcone, F.; Baena, J.D.; Medina, F.; Martin, F.; Sorolla, M. A new LC series element for compact bandpass filter design. IEEE Microw. Wirel. Compon. Lett. 2004, 14, 210-212. [CrossRef]

82. Baena, J.D.; Marques, R.; Medina, F.; Martel, J. Artificial magnetic metamaterial design by using spiral resonators. Phys. Rev. B 2004, 69, 4402. [CrossRef]

83. Schurig, D.; Mock, J.J.; Smith, D.R. Electric-field-coupled resonators for negative permittivity metamaterials. Appl. Phys. Lett. 2006, 88, 6681. [CrossRef]

84. Ahn, D.; Park, J.S.; Kim, C.S.; Kim, J.; Qian, Y.X.; Itoh, T. A design of the low-pass filter using the novel microstrip defected ground structure. IEEE Trans. Microw. Theory 2001, 49, 86-93. [CrossRef]

85. Safwat, A.M.E.; Podevin, F.; Ferrari, P.; Vilcot, A. Tunable bandstop defected ground structure resonator using reconfigurable dumbbell-shaped coplanar waveguide. IEEE Trans Microw. Theory 2006, 54, 3559-3564. [CrossRef]

86. Falcone, F.; Lopetegi, T.; Baena, J.D.; Marques, R.; Martin, F.; Sorolla, M. Effective negative- $\varepsilon$ stopband microstrip lines based on complementary split ring resonators. IEEE Microw. Wirel. Compon. Lett. 2004, 14, 280-282. [CrossRef]

87. Velez, A.; Aznar, F.; Bonache, J.; Velazquez-Ahumada, M.C.; Martel, J.; Martin, F. Open Complementary Split Ring Resonators (OCSRRs) and Their Application to Wideband CPW Band Pass Filters. IEEE Microw. Wirel. Compon. Lett. 2009, 19, 197-199. [CrossRef]

88. Naqui, J.; Duran-Sindreu, M.; Martin, F. Differential and Single-Ended Microstrip Lines Loaded with Slotted Magnetic-LC Resonators. Int. J. Antenn. Propag. 2013, 2013. [CrossRef]

89. Muñoz-Enano, J.; Velez, P.; Herrojo, C.; Gil, M.; Martin, F. On the Sensitivity of Microwave Sensors based on Slot Resonators and Frequency Variation. In Proceedings of the 2019 International Conference on Electromagnetics in Advanced Applications (ICEAA), Granada, Spain, 9-13 September 2019; pp. 112-115.

90. Drake, E.; Medina, F.; Horno, M. Quick computation of [C] and [L] matrices of generalized multiconductor coplanar waveguide transmission lines. IEEE Trans. Microw. Theory Tech. 1994, 42, 2328-2335. [CrossRef] 